\title{
How to Set up a Thrombectomy Service
}

\section{The St. Petersburg Experience}

\author{
A. V. Savello ${ }^{1,3} \cdot$ I. A. Vozniuk ${ }^{1,2} \cdot$ J. Fiehler ${ }^{4} \cdot$ K. Y. Orlov ${ }^{5,6}$
}

๑) Springer-Verlag GmbH Germany, part of Springer Nature 2020

In the last decade the number of stroke patients in the Russian Federation ranged from ca. 495,000 to 510,000 according to Rosstat (Russian Federal Statistics Service) rendering it the second leading cause of death in Russia. The burden of stroke reached an unprecedented scale particularly in large cities. Recent data on St. Petersburg suggested that out of 5.35 million residents, nearly 3 million aged between 15 and 65 years are active and able to work.

The emergence of endovascular thrombectomy (ET) and the outcomes of the first related studies suggested the possibility of achieving a breakthrough in stroke treatment and created the need for ET implementation in routine clinical practice [1]. As early as 2015, the Association of Russian Neurosurgeons developed clinical guidelines for endovascular interventions during acute cerebrovascular accidents (CVA). Considerable changes were observed after implementing a 2-tiered network of vascular centers for treatment of patients with acute pathologies of the circulation. Over a period from 2014 to 2019 , the stroke mortality rate in Russia decreased by $20 \%$ (22 cases per 100,000 people) while the overall mortality rate in the population remained constant at about 88 cases per 100,000 people during 2019 .

A. V. Savello

alexander.savello@gmail.com

1 S.M. Kirov Military-Medical Academy, St. Petersburg, Russian Federation

2 I.I. Djanelidze Emergency Care Research Institute, St. Petersburg, Russian Federation

3 V.A. Almazov National Medical Research Center, St. Petersburg, Russian Federation

4 Department of Neuroradiology, University Medical Center Hamburg-Eppendorf, Hamburg, Germany

5 E.N. Meshalkin National Medical Research Center, Novosibirsk, Russian Federation

6 Russian Endovascular Neuro Society (RENS), Moscow, Russian Federation
The endovascular interventions in stroke patients performed at St. Petersburg Comprehensive Stroke Centers faced a number of challenges. First, in relation to its large population, St. Petersburg had an insufficient number of specialized departments with suitable diagnostic and treatment facilities and was lacking interventionalists to treat acute cerebrovascular pathologies. The departments with a cerebrovascular focus were mostly found in highly specialized institutions that were not designed as centers for acute stroke cases. Therefore, it was deemed appropriate to create ET capacities in interventional radiology departments that were already established for patients with acute coronary events. Second, the overwhelming majority of specialists working in those departments had little practical experience in neurology and neurosurgery. Despite their initially limited skills for operating in the cerebrovascular system, they had considerable endovascular experience in coronary and peripheral arteries. To familiarize these specialists with acute ischemic stroke treatment, St. Petersburg started hosting training sessions and master classes on ET in patients with acute CVA. When necessary, leading interventional neuroradiologists offered distant consultation to the stroke center surgeons. Since 2018, ET procedures are financed by the Mandatory Health Insurance Fund in Russia. As a result of organizational, methodical and educational efforts, a significant increase was observed in the number of intravenous thrombolytic treatments (IVT) and ET procedures in the vascular centers of the city (Fig. 1).

The number of IVT cases increased from 161 (2014) to 1492 (2019), while ET increased from 25 (2014) to 650 (2019). In the same period, the hospital mortality of stroke patients in St. Petersburg decreased from $21.3 \%$ (2014) to $15.8 \%$ (2019). This trend is in line with a general decrease in deaths from ischemic stroke-20.6\% (2014) to $14.3 \%$ (2019). These data suggest a causal association between the increase in ET treatment and the reduction in hospital and total mortality in stroke patients at the same time. Currently, 16 stroke centers are treating CVA patients in 


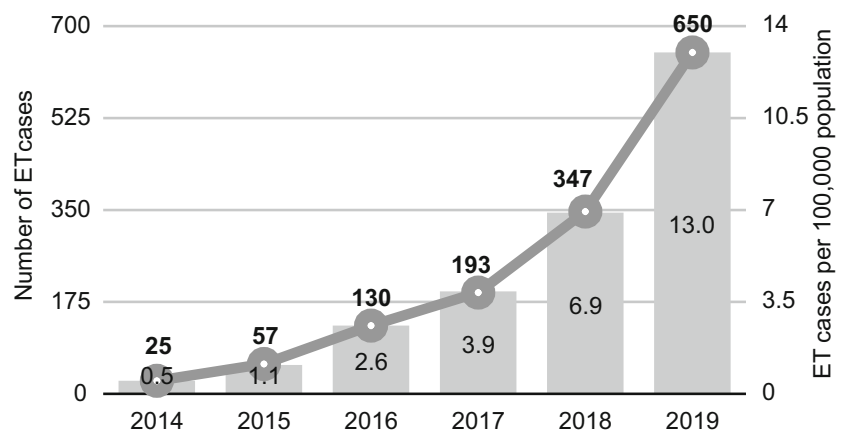

Fig. 1 Annual number of endovascular thrombectomies in St. Petersburg

St. Petersburg. Among them, there are 9 comprehensive stroke centers (CSC) and 7 primary stroke centers (PSC) with $30-120$ beds and the total number amounting to 927 (estimated requirement is 1060 beds). Patients with acute CVA receive specialized beds at a CSC or PSC in 95\% cases (2016-2019), the share of patients hospitalized during the first day after symptom onset accounts for $91 \%$ (2019). The overwhelming majority of candidates for ET are sent directly to a CSC with capabilities for performing IVT and/or ET.

The data on patients who underwent ET over a period from 2017 to 2019 are organized by filling out a special case record form, an electronic table in the cloud service. The entries are checked and validated by three independent experts experienced in endovascular neuroradiological interventions for at least 10 years. The data available at the time of writing indicate that there were 1174 patients $(600$ males and 574 females, median age 69 years) with a large vessel occlusion (LVO) who were treated in the acute period of ischemic stroke (Fig. 1). Every third patient (33.1\%) underwent ET combined with IVT, $20.7 \%$ patients had acute CVA and underwent ET. The most frequent pre-existing diseases included hypertensive disease $(84.2 \%)$, coronary heart disease $(61.5 \%)$ and atrial fibrillation (43.5\%). During ET, approximately one third of the patients (27.8\%) received antiplatelet therapy and $20.3 \%$ were under anticoagulant treatment.

Occlusions of the carotid arterial system were the most frequent occlusion sites, with the M1 segment of the middle cerebral artery (MCA) and the internal cerebral artery (ICA) involved in the majority of cases $(70.4 \%)$. The vertebrobasilar system was affected in $13 \%$ of patients who underwent ET, with occlusions of the basilar artery as the most frequently observed location (8.9\%). The median time from stroke onset to CSC admission was $118 \mathrm{~min}$. It took $268 \mathrm{~min}$ from symptom onset to reperfusion for strokes occurring outside of a hospital and 152min for already hospitalized patients. Thrombus aspiration was more frequently used than primary reperfusion $(62.9 \%)$. Thrombus extrac- tion by a stent-retriever was used as first-line strategy in $28 \%$ of the cases. When performing thrombus aspiration or extraction, the frequency of changing strategies was comparable and amounted to $23 \%$ and $24.9 \%$ respectively, $23.7 \%$ on average in our series. It is worth mentioning that during the last 3 years there was a trend towards reducing the number of stent-retrievers and to more frequently use aspiration catheters. In 2017, stent-retrievers and aspiration catheters were applied as the first-line strategy in $71.8 \%$ and $23.2 \%$ of cases, respectively, in 2018 this ratio changed to $40.9 \%$ and $47.8 \%$ and in 2019 to $9.9 \%$ and $80.7 \%$, respectively.

The total rate of successful reperfusions (modified Thrombolysis in Cerebral Infarction scale [mTICI] score 2b-3) was $81.3 \%$, with complete reperfusions (mTICI 3) in $65 \%$ of the patients and minimal differences between the arteries of the carotid and vertebrobasilar systems. The ET complications included embolization into a new territory (65 patients, 5.5\%), arterial dissection (18 cases, $1.5 \%)$, vasospasm requiring treatment (10 cases, $0.9 \%)$ and hematoma localized at the point of femoral puncture (10 cases, 0.8\%). Symptomatic hemorrhagic transformations (ECASS II criteria [2]) totally were observed in $158 / 1174(13.5 \%)$ patients $(135 / 1021$ [13.2\%] in the carotid system and in 23/153 [15\%] in the vertebrobasilar circulation). The rate of good functional outcome (mRS $0-2)$ at discharge in patients who underwent ET in the anterior circulation was $31.8 \%$, with a mortality of $32.3 \%$. In patients with stroke in the vertebrobasilar circulation, these values accounted for $24.3 \%$ and $52.9 \%$, respectively.

The ET results achieved in St. Petersburg CSC differed significantly from those reported in the randomized trials. One of large meta-analyses which included 8 randomized studies and 2423 patients [3] found a 90-day mortality of $15.8 \%$ following ET in the carotid systems, while the share of good functional outcomes was $44.6 \%$ (in our study it was $31.8 \%$ at discharge). At the same time, when comparing the St. Petersburg CSC data with real-world data from other practicing health institutions, the differences are not so significant. According to the German Stroke Registry [4] 28.5\% patients died and $36.7 \%$ had good functional outcomes after ET in the carotid artery system after 90 days, which is close to our data. The outcomes differ from the results of randomized trials in other publications as well [5] and in a senior age group in particular [6]. When comparing ET outcomes in the vertebrobasilar system with those provided in the German registry [3], there are substantial differences: $30.9 \%$ patients died after 90 days (in this study this figure was $52.9 \%$ at discharge) and $37.7 \%$ had good functional outcomes (in this study $24.3 \%$ at discharge). At the same time, according to another study, 90-day mortality after ET in the vertebrobasilar system was $44.2 \%$ [7]. It is concluded that a comprehensive system for delivery of ET in stroke patients was created and implemented on 
the basis of the existing system in the large metropolitan area of St. Petersburg in a relatively short time period. The participating institutions use interventional radiology methods of diagnostics and treatment and deliver good technical results of endovascular interventions (successful reperfusion in $81.3 \%$ of the cases). The operators currently prefer thrombus aspiration instead of stent-retrievers as first-line treatment.

The number of ET for ischemic patients with acute CVA at St. Petersburg CSCs keeps growing from year to year. Tentatively, in 2020 there might be a need for 800-1200 interventions with the number of combined (ET + IVT) reperfusion therapies growing as well. The expanding time window for ET of up to $24 \mathrm{~h}$ is one additional factor that is further increasing the need for ET. During this further growth, further challenges must be faced, such as optimizing the patient logistics at a prehospital stage by decreasing the transportation time to the CSC and also within the hospital by shortening the time interval between imaging and groin puncture. Of great importance on the agenda is the improvement of further medical care after the acute therapy and further developing the registry of patients undergoing ET, which will be useful for assessment of long-term functional outcomes.

Conflict of interest A.V. Savell: consultant for Medtronic. I.A. Vozniuk and K.Y. Orlov declare that they have no competing interests. J. Fiehler: research support from the German Ministry of Science and Education (BMBF), German Ministry of Economy and Innovation (BMWi), German Research Foundation (DFG), European Union (EU), Hamburgische Investitions- und Förderbank (IFB), Medtronic, Microvention, Philips, Stryker. Consultant for Acandis, Bayer, Boehringer Ingelheim, Cerenovus, Medtronic, Microvention, Penumbra, Stryker. Stockholder in Tegus Medical, Managing director: Eppdata GmbH.

\section{References}

1. Turc G, Bhogal P, Fischer U, Khatri P, Lobotesis K, Mazighi M, Schellinger PD, Toni D, de Vries J, White P, Fiehler J. European Stroke Organisation (ESO)-European Society for Minimally Invasive Neurological Therapy (ESMINT) guidelines on mechanical thrombectomy in acute ischemic stroke. J Neurointerv Surg. 2019;11:535-8.

2. Hacke W, Kaste M, Fieschi C, von Kummer R, Davalos A, Meier D, Larrue V, Bluhmki E, Davis S, Donnan G, Schneider D, DiezTejedor E, Trouillas P. Randomised double-blind placebo-controlled trial of thrombolytic therapy with intravenous alteplase in acute ischaemic stroke (ECASS II). Second European-Australasian Acute Stroke Study Investigators. Lancet. 1998;352:1245-51.

3. Badhiwala JH, Nassiri F, Alhazzani W, Selim MH, Farrokhyar F, Spears J, Kulkarni AV, Singh S, Alqahtani A, Rochwerg B, Alshahrani M, Murty NK, Alhazzani A, Yarascavitch B, Reddy K, Zaidat OO, Almenawer SA. Endovascular thrombectomy for acute ischemic stroke: a meta-analysis. JAMA. 2015;314:1832-43.

4. Wollenweber FA, Tiedt S, Alegiani A, Alber B, Bangard C, Berrouschot J, Bode FJ, Boeckh-Behrens T, Bohner G, Bormann A, Braun M, Dorn F, Eckert B, Flottmann F, Hamann GF, Henn KH, Herzberg M, Kastrup A, Kellert L, Kraemer C, Krause L, Lehm M, Liman J, Lowens S, Mpotsaris A, Papanagiotou P, Petersen M, Petzold GC, Pfeilschifter W, Psychogios MN, Reich A, von Rennenberg R, Röther J, Schäfer JH, Siebert E, Siedow A, Solymosi L, Thonke S, Wagner M, Wunderlich S, Zweynert S, Nolte CH, Gerloff C, Thomalla G, Dichgans M, Fiehler J. Functional outcome following stroke thrombectomy in clinical practice. Stroke. 2019;50:2500-6.

5. Wiącek M, Kaczorowski R, Homa J, Filip E, Darocha J, Dudek D, Guz W, Bartosik-Psujek H. Single-center experience of stent retriever thrombectomy in acute ischemic stroke. Neurol Neurochir Pol. 2017;51:12-8.

6. Alawieh A, Chatterjee A, Feng W, Porto G, Vargas J, Kellogg R, Turk AS, Turner RD, Imran Chaudry M, Spiotta AM. Thrombectomy for acute ischemic stroke in the elderly: a 'real world' experience. J Neurointerv Surg. 2018;10:1209-17.

7. Gory B, Mazighi M, Blanc R, Labreuche J, Piotin M, Turjman F, Lapergue B. Endovascular treatment in ischemic stroke research I. Mechanical thrombectomy in basilar artery occlusion: influence of reperfusion on clinical outcome and impact of the first-line strategy (ADAPT vs stent retriever). J Neurosurg. 2018;129:1482-91. 